\title{
Mikhail A. Vorotyntsev-a tribute on the occasion of his 70th birthday
}

\author{
Ekaterina V. Zolotukhina ${ }^{1}$ • Doron Aurbach ${ }^{2}$
}

Received: 28 June 2015 /Revised: 6 July 2015 / Accepted: 8 July 2015 / Published online: 23 July 2015

(C) Springer-Verlag Berlin Heidelberg 2015

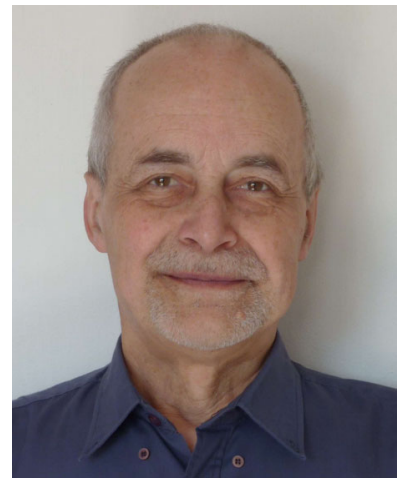

"Le savant doit ordonner; on fait la science avec des faits comme une maison avec des pierres; mais une accumulation de faits n'est pas plus une science qu'un tas de pierres n'est une maison"

"The savant creates order: he builds science from facts just as a house is built from stones. But a collection of facts is no more a science any more than a pile of stones is a house."

\section{Henri Poincaré,}

Science and Hypothesis

$\mathrm{PhD}$ and Doctor of Sciences in Physics and Mathematics (Habilitation), Research Professor and Directeur de Recherche

Ekaterina V. Zolotukhina

zolek.ya@yandex.ru

1 Institute of Problems of Physical Chemistry RA, Academica Semenova Prospect, 1, 142432 Chernogolovka, Russia

2 Department of Chemistry, Bar-Ilan University (RA), 52900 Ramat-Gan, Israel
Emerite, Member of Academia Europaea, Mikhail A. Vorotyntsev is internationally recognized as a bright researcher and organizer of international meetings and research projects, well known for his enthusiastic, energetic, and independent-minded attitude to science.

After graduation from M. V. Lomonosov Moscow State University, M. A. Vorotyntsev continued research and studies for a $\mathrm{PhD}$ degree in the department of mechanics and mathematics (specializing in Chemical Mechanics at the Prof. V. G. Levich chair). He defended his $\mathrm{PhD}$ thesis "Kinetics of Charge Transfer in Polar Media" in Physical and Mathematical Sciences in 1971 under the supervision of Prof. R.R. Dogonadze and Dr. A.M. Kuznetsov. Doctor of Sciences degree (Habilitation) was awarded to him in 1987 by Institute of General Physics, Academy of Sciences of the USSR for his doctoral thesis "Theory of Equilibrium and Kinetic Phenomena at Metal/Electrolyte Solution Interface". His academic career in Russia included positions of assistant professor in the department of mechanics and mathematics at M. V. Lomonosov Moscow State University (1970-1978) as well as Senior, Leading and then Principal Researcher (19791998) in the theoretical department at the famous A.N. Frumkin Institute of Electrochemistry, Academy of Sciences of the USSR. In the period of 1992-1995 he carried out research in several institutions outside Russia, including the Fritz-Haber institute at the Max-Planck Institute in Berlin (Germany), Pierre \& Marie Curie University (Paris, France) and the Institute of Physical Chemistry at the University of Freiburg (Germany). Then he served as a full professor at the Department of Applied Physics, Fukui University (Japan) in 1995-1997. The next stage of his academic carrier is connected to Bourgogne University (Dijon, France). There he served as an associate professor and research director, affiliated with the CNRS. Since 2011, Prof. Vorotyntsev is a research director emeritus in this university. In parallel, since 2005, he was 
delivering courses at the Faculty of Chemistry of the M. V. Lomonosov Moscow State University. After his retirement in France, he organized an experimental laboratory at the Institute for Problems in Chemical Physics, Russian Academy of Sciences (Chernogolovka). More recently he has become a research professor at the D. I. Mendeleev University of Chemical Technology of Russia (Moscow).

Since 1995 M. A. Vorotyntsev is leading various editorial and organizational activities: a guest editor for Electrochimica Acta (special issues in 1996, 2001, 2004, 2005, 2008, 2011, 2014, 2015) and Journal of Solid State Electrochemistry (special issues in 2007, 2011), Member of the advisory board of Electrochimica Acta (2011-2014), Elected representative of Russia in the International Society of Electrochemistry (ISE, since 2014), vice-chairman of division 2 (1995-1996, 1997 1998, and 1999-2000) and of division 4 (2011-2012, 20132014, and 2015-2016) of the ISE, the academic secretary of the Moscow Seminar in Electrochemistry (since 2013), chairman and/or organizer of over 20 international conferences (three conferences being actually under preparation), including his "favorite child": the WEEM ("International Workshop on Electrochemistry of Electroactive Materials") series of conferences initiated by him in 1995, with the latest workshop help in Bad Herrenalb (Germany) in June 2015.

M. A. Vorotyntsev is equally active in research. Besides a monograph on electrostatics of non-local media, he has published over 200 review and research papers in prestigious international journals in chemistry, physics, and biology. The annual number of such publications has even increased the last years. These publications are extensively cited by other researchers: Overall number of their citations since 1989 exceeds 3400 , recent annual citation numbers are about 200, Hindex is 33. A characteristic feature of his publications is the extended period of their citations. Many of them are cited during several decades.

His research contributed so much for both theoretical and experimental areas. Educated by the V. G. Levich school of theoretical physics, he has been specializing for more than 30 years in the following areas and topics: theories for electrochemical and physicochemical phenomena, quantum-mechanical description of electron and proton transfer in polar solvents and at metal/electrolyte solutions interfaces, light absorption by solute species in polar solvents, charge-separation processes in photosynthetic reaction centers, electrostatic phenomena in polar media, interfacial structure and ionic transport in solid electrolytes, electric double layer effects in kinetics of electrochemical reactions, electrostatics of thin solid films, interfacial structure at charged electrodes with non-uniform surface properties, ionic transport near solid walls at turbulent flow regimes, electrochemical current fluctuations induced by turbulent pulsations, the "mirage effect" technique to study interfacial ion fluxes, transport phenomena in fluid and solid media, passage of direct or alternating current through conducting media, impedance of electroactive films, systems with a mixed interfacial exchange, twodimensional ionic ensembles, interaction potentials between adsorbed ions and/or dipole molecules, ion adsorption isotherms and correlation properties of adsorbed ion ensembles, electrochemical phenomena in electronically conducting polymer films, kinetics of redox reactions at the surface films/solution interfaces, intercalation electrodes and more.

Since 2000 , the center of his research activity moved towards more experimental work. His laboratory in Dijon was specializing in synthesis and characterization of novel electroactive polymers as well as inorganic particles-polymer nanocomposites. More recently, experimental work in these areas under his supervision has been initiated in Russia. Results of these studies have been and are being published in top international journals of electrochemistry and physical chemistry. At the same time, he is retaining his high theoretical capabilities, as it is evident by the work in his latest new areas: theory of transport processes inside halogen oxo-anion flow batteries and work on autocatalytic mechanisms of electrochemical reactions.

M. A. Vorotyntsev is often invited to deliver plenary and keynote lectures at international conferences. His work for the entire electrochemistry community and efforts in science education are impressive.

He makes all possible efforts to transfer his enormous research experience and knowledge in science to the younger generations. His great dedication to all his research associates over the year: post-doctoral fellows, $\mathrm{PhD}$ graduate and undergraduate students, should be emphasized. Many of them have already become bright scientists.

These scientific activities are inseparably linked to another side of his life: his hobbies of boating along mountain rivers and enjoying long-distance walks.

This combination of intensive intellectual and physical activities illustrates perfectly the versatility of this bright personality. This combination of intensive intellectual and physical activities illustrates perfectly the versatility of this bright personality. One may say at his 70th birthday that he is actually on the rising stage of his creative successes (12 papers in international journals published from January 2014 till June 2015, in combination with numerous mountain rivers passed within the same period), with his evident intention to jump over further barriers.

This special issue in a leading journal of chemistry is one of the best ways to celebrate his 70th birthday. It is a compendium of first rate papers, written by friends and colleagues, all of whom appreciating so much his great contribution to our community, in a wide spectrum of topics, reflecting well his broad scope of topics of expertise. 
We all wish him best health, happiness, and continuous creative life.

The guest editors of this special volume

Ekaterina Zolotukhina

Doron Aurbach

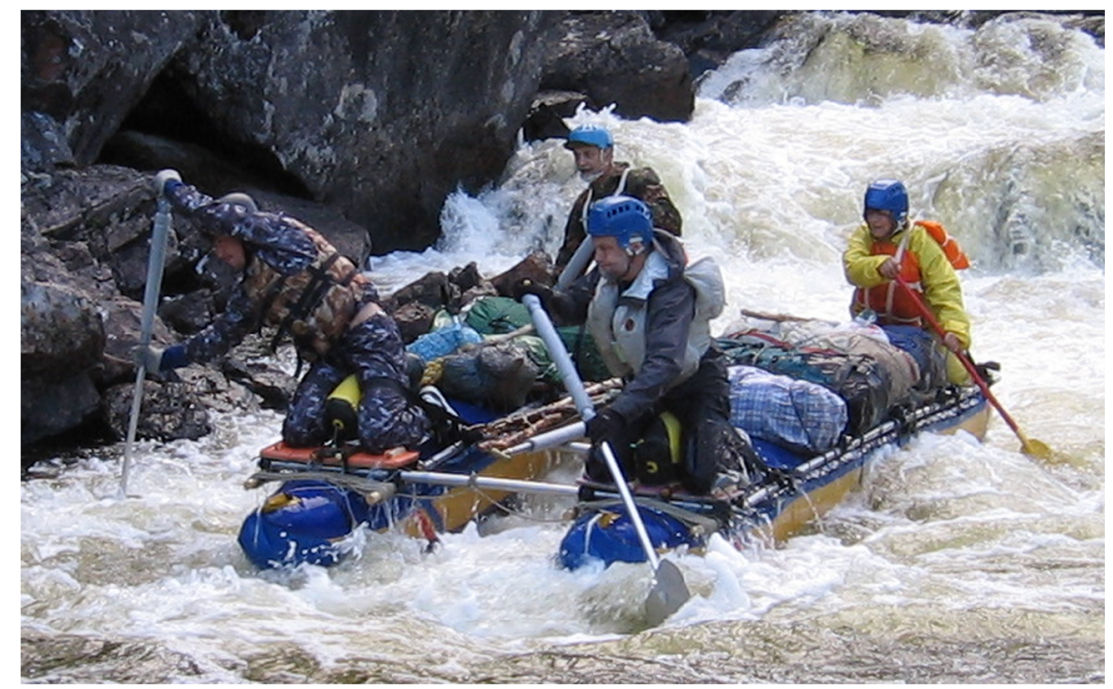

Kutsa-2010

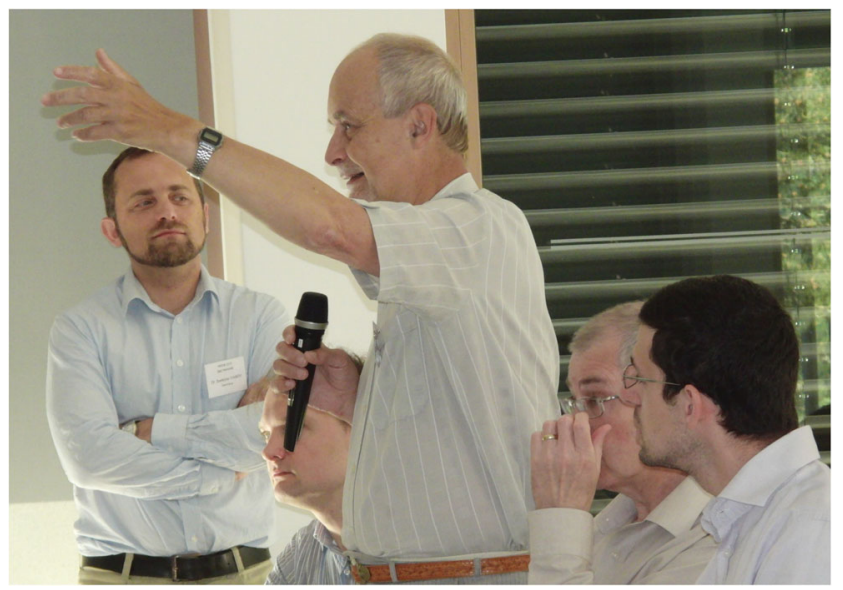

WEEM-2015 